\title{
Postgraduate Forum on Genetics and Society: Report on the Ninth Colloquium.
}

\section{ANDREW BARTLETT, JAMIE LEWIS \& INGRID HOLME}

Initiated in 1998, the Postgraduate Forum on Genetics and Society (PFGS) provides a common forum for early-career academics from a variety of different fields, including sociology, psychology, law and philosophy, to engage with each other in productive dialogue. The annual PFGS Colloquium has a tradition of enabling those with interests in genetics and society to present their work to an audience of peers from a range of disciplines, traditions and institutions. These gatherings promote debate and dissemination in a rich inter-disciplinary setting and provide opportunities for crossfertilisation of methods, theory and findings. They give the next generation of academics the opportunity to identify emerging research themes and the chance to attend free workshops, on such topics as methodology and ethics, led by established academics.

Cardiff University and CESAGen played host to the Ninth PFGS Colloquium between $31^{\text {st }}$ August and $2^{\text {nd }}$ September 2005, generously funded by the Genomics Forum. The title of the colloquium was 'The Genetic Information Age', an attempt to concisely articulate the central theme; a concern with the philosophical, scientific, legal and social implications of understanding genetic knowledge as information, or genetic information as knowledge. As with the PFGS, this theme was intended to be forward looking, urging consideration of the possible futures of the social and scientific landscape that current members of the PFGS will explore in the course of their careers. However, as Jon Turney argued when opening the colloquium with a keynote address, 'The Genetic Information Age' may well have already taken place.

Five themes were central to the postgraduate presentations:

1. The generation of genomic and post-genomic knowledge

2. The engagement of genomic science and scientists with the wider community

3. The development, structure and maintenance of intellectual property frameworks

4. The international context of genomics

5. The ideology of genetics

\section{The generation of knowledge}

A number of papers addressed the issues of scientific development, labour and organization. In the first session Andrew Bartlett (Cardiff University) presented a paper arguing that the development of 'big' biological science might have unintended effects on the generation of scientific knowledge. His paper suggests that a lack of attention has been paid to the hierarchical character of laboratory life within research. He argued that a scientific organisation maximising 'functional rationality' might lead to dissolution of the norms of the scientific community and an alienation of the scientists from the knowledge they create. In the same session, Miguel GarciaSancho (Imperial College) challenged the conventional account of the development of molecular sequencing strategies. He argued that the development of DNA sequencing 
was not simply a linear progression from protein sequencing that could be accounted for in purely technical terms. Garcia-Sancho argued that the development of DNA sequencing was directly influenced by the conceptualisation of DNA as information. This session gave us an image of knowledge production as an activity involving both the scientist as an individual, with personal norms and values, and the scientist as a member of a community, sharing concepts and metaphors.

The issue of how 'mutual' concepts and metaphors are created within scientific communities was explored by Bart Penders (Maastricht University). His paper stressed the different 'style boundaries' that exist between 'wet' scientists (biologists), and 'dry' scientists (bioinformaticians). Jamie Lewis (Cardiff University) further developed this issue, exploring the difference in the levels of standardisation in proteomics research, making reference to the Proteomics Standards Initiative, and between the dry and the wet laboratory, and the effects that this might have on knowledge production.

The role played by non-humans in the production of knowledge was emphasised in the paper presented by Shirlene Badger (University of Cambridge). This explored how, in the case of obesity, mouse models were used to directly inform research on children. These papers illustrate the methodological importance of qualitative studies of science with regard to understanding the process of knowledge production. This was articulated by Megan Clinch (London School of Economics) in a paper that called for a programme of 'narrating genes in context'.

\section{Community engagement}

'Community engagement' is here used as to describe the wider context of genomic knowledge, including public and political engagement with the rhetoric of genetics and genomics. Aryn Martin (Cornell University), who is in the closing stages of her $\mathrm{PhD}$ work, presented a paper that explored the concept of chimeras and mosaics. Her paper argued that cells have a materiality that can escape the body and enter institutions of governance, kinship and healthcare. Martin challenged the development of a one-to-one biographical correspondence between cells and people, presenting ethnographic case studies where the genetic variability of cells invokes a multiplication of personhood. Here, it is not so much that the science is new but rather that new people are constructed.

Connor Douglas (University of York) discussed the role of patients in co-constructing medical genetic technologies. He argued that the key issue here is not the ontological question of whether genetic information is of a different kind from other kinds of medical knowledge, but whether patients perceive genetic information as being categorically distinct. Ingrid Geesink (Cardiff University) presented a richly detailed paper that discussed the role of regulatory actors in shaping the technology of tissue engineering, with a particular emphasis on issues of risk and safety.

David Larsen (University of Cambridge) presented a paper that discussed the biopolitics of biotechnology. He argued that the primary interest of the British state in managing its citizen's illnesses is undergoing a process of realignment. Whereas the traditional model is for state intervention in the management of disease in order to 
increase the productivity of economic activities outside of the hospital and clinic, the emerging model is for the state to contribute to the endogenous growth of the biotechnology industry and their "reflexively" spiralling markets.

\section{Intellectual property}

It could be argued that the notion of genetic knowledge as intellectual property is a consequence of a perspective that holds genetics to be primarily an informational science. The key papers at the PFGS colloquium that addressed the theme of intellectual property were delivered in a themed session on the second day of colloquium. Chris Hamilton (London School of Economics) discussed the tension between the promissory, progressive rhetoric of 'bioprospecting' and the rhetoric of 'biopiracy' that stressed the inequalities of the relationships involved in 'bioprospecting'. This confrontation has found a site of particular contest in the arena of intellectual property rights; ought living things, and/or parts of living things, be patented?

Adam Bostanci (Exeter University) explored the arguments used by the U.S. Patent and Trademark Office (USPTO) to reject patent application on microbial genomes. He analysed the USPTO examination files relating to three applications to patent whole genomes. These were not deemed to be patentable inventions, whereas genes and open reading frames were. This paper raised questions of how divisions are drawn between the categories of invention and discovery, between an electronic genome sequence and its biochemical equivalent, and between a genome and a gene. Both these papers emphasised the changing boundaries between public and private agencies and raised issues surrounding responsibilities of institutional structures.

Several papers addressed issues of the general property structures that have developed with and are utilised by genetics and genomics. Both Larsen and Rebecca Hanlin (University of Edinburgh) discussed the importance of international property rights in modern healthcare systems. Adele Langlois (Open University) explored the impact of the inequalities in the proprietary structure of genetics and genomics in the global South.

\section{International context}

Langlois questioned whether existing initiatives, such as a series of UNESCO declarations and the Global Genomics Initiative, will be able to bridge what she describes as the 'genomics divide'. She asked whether the global South will be able to make use of the 'global public good' of genomics, or will it be the case that 'The Genetic Information Age' will produce greater inequality?

The international context of genetic knowledge and technology was explored by a number of other participants. Matthew Harsh (University of Edinburgh) discussed the governance of biotechnology in Kenya and Uganda. These nations have similar levels of biotechnology and similar biosafety policies. However, discourses of openness and mutuality present a more transparent and participatory image of biotechnological governance in Uganda than the governance regime employed in Kenya, which is marked by discourses of closed networks, specifically the 'Nairobi biotech mafia'. 
Chamu Kuppuswamy (University of Sheffield) addressed the 10/90 gap in terms of genomics. Following on from the Commission on Health Research for Development statement, in 1990, that only 10 per cent of the resources allocated for health research are directed to 90 per cent of the world's health problems, Kuppuswamy asked whether a similar pattern will be found in the distribution of the medical fruits of genomic science. She argued, illustrating her point with the case of AIDS drugs in South Africa, that inequities in healthcare are likely to be exacerbated by the advent of "The Information Age". Her colleague Yog Upadhyay (University of Sheffield) examined the North-South divide in agricultural biotechnology, arguing that the development of technologies shaped by the interests of the food industry of the North have a deleterious impact on agricultural practice and food security in the South.

The second day of the colloquium saw a session devoted to Canadian perspectives on 'The Genetic Information Age'. Anne Dijkstra (University of Twente) discussed the engagement of the wider society with genetic science, using divergent 'publics' as the object of her study rather than a homogenous 'public'. She compared debates on biotechnology and genomics in Canada with those taking place in the Netherlands. Grace Reid (Cardiff University) delivered a paper exploring social representation of cloning in Canada. A member of the Cardiff School of Journalism, Media and Cultural Studies, Reid presented the results of her textual analysis of newspaper articles on cloning and a series of focus groups. She discussed the framing of the benefits of cloning and how these are weighed against moral and ethical concerns.

\section{The ideology of genetics}

The final session of postgraduate presentations discussed the idea of an 'ideology of genetics'. Kean Birch (University of Glasgow/Oxford Brookes University) discussed the development of ideological networks within and around the life science industries wedded to 'economic' rather than 'technical' success. Jane Miller (University of Sheffield) asked if the future of medicine was genetic. She pointed out that historically, major improvements in health care have been the result of social programmes, and that genetics is just a small part of our health care requirements. Miller suggested that political enthrallment with the promises of genetic knowledge could have serious consequences if this entails a diversion from conventional public health strategies. Kate Weiner (University of Nottingham) delivered a critique of the notion of geneticization, a concept that has been used across a wide range of research since the early 1990s. Her paper used the work of PFGS alumni Adam Hedgecoe on the rhetoric of science to suggest that we need to consider how we perform and disseminate critical research on genetics while not playing an active role in the construction of 'hype'. Birch drolly proposed that we ought to encourage others to ignore our work so as not to contribute to the 'hype'.

\section{Conclusion}

The Ninth PFGS Colloquium attracted 51 attendees over the three days, including the guest speakers; Jon Turney (University College London) who opened the colloquium, Andrew Webster (University of York) who led a research ethics workshop, Kate Stewart and Bruce Mason (both Cardiff University) who led a pair of themed training workshops on the use of internet communication in social research, and Joan Haran (Cardiff University) who provided an after-dinner speech on the evening of the 
second day. The colloquium closed with a panel discussion on the notion of 'The Genetic Information Age' involving Ian Brewis (Cardiff University), Jane Calvert (Exeter University), Katie Featherstone (Cardiff University) and Buddug Williams (Genetic Interest Group). The key measures of the colloquium's success however are the wealth and quality of the postgraduate papers that were presented.

30 postgraduate papers were delivered. While the papers discussed in this review are an attempt to provide a representative picture, the full set of colloquium abstracts can be found on the PFGS website.

\section{For further information}

The PFGS manages a website at http://pfgs.org/ and a bulletin board at http://pfgs.org/phpBB/index.php. The website contains information on previous colloquia, member profiles and details of upcoming events. The bulletin board is a site for direct discussion of issues of interest to researchers working in the field of genetics and society. To become a member of the PFGS please visit the website or contact any of the authors of this paper. Membership is free.

\section{Note from the Genomics, Society and Policy Editors:}

There will be a PFGS Special Issue of the Genomics, Society and Policy Journal published in December 2006, which will feature papers related to the theme of the Ninth PFGS Colloquium, The Genetic Information Age.

Any enquiries can be directed to PFGS Co-Editor, Adam Bostanci, at a.w.s.bostanci@ex.ac.uk. 